\title{
CpG DNA analysis of bacterial STDs
}

\author{
Martin Singer ${ }^{1 \dagger}$, Dewi J de Waaij ${ }^{1 \dagger}$, Servaas A Morré ${ }^{1,2}$ and Sander Ouburg ${ }^{1 *}$
}

\begin{abstract}
Background: Bacterial infections in the genital tract frequently result in morbidity through a variety of inflammation based symptoms. One component of the bacteria that may trigger host inflammatory response is their DNA. CpG motifs in this DNA are known targets for Toll-like receptor 9 (TLR9), which is a pathogen-recognition receptors focusing on CpG DNA. The activation of TLR9 induces the NF-KB inflammatory pathway. This study aims to provide a broad view of the inflammatory potential of CpG DNA motifs in bacteria related to genital diseases: C. trachomatis, E. coli, N. gonorrhoeae, G. vaginalis, H. ducreyi, L. crispatus, L. gasseri, M. hominis, M. genitalium, T. pallidum, and U. urealyticum.

Methods: Publicly available genomic sequences of the bacterial species and strains have been analyzed in silico to produce a $\mathrm{CpG}$ index number. This $\mathrm{CpG}$ index number shows the relative inflammatory potential of the genome and has previously been used in a study by Lundberg et al. (2003). Higher CpG index values suggest a strong CpG induced inflammation potential during infection and vice versa.

Results: The highest observed CpG index belongs to G. vaginalis with a value of 26,2, suggesting a strong pro-inflammatory potential when in contact with TLR9. The lowest index belongs to N. gonorrhoeae with a value of $-79,5$, suggesting a strong immunoinhibitory effect on TLR9 contact. Interestingly, Lactobacilli showed a mean CpG index value of 4,2, suggesting a weak inflammatory potential.

Discussion: Our results show varying $\mathrm{CpG}$ index values between bacterial species. Comparison of $\mathrm{CpG}$ indices with the clinical course of several pathogens shows the CpG index helps clarify the clinical course of infection. However, we found no links between $\mathrm{CpG}$ index values and either obligate pathogenicity or facultative pathogenicity through bacterial vaginosis. Lactobacilli showed relatively low CpG indices which do suggest a lower inflammatory potential from these bacteria.
\end{abstract}

Conclusions: Our results show varying CpG index values between bacterial species, which may help clarify the clinical course of infection, and may help diagnosis.

\section{Background}

Bacterial Sexually Transmitted Diseases (STD) and Genital Tract Infections (GTI) can cause high levels of morbidity, are often accompanied by social stigma, and are frequently widespread [1]. Symptoms can range from slight inflammation and discharge to infertility and death. In these diseases, inflammatory responses may not always have the positive effect of initiating immune responses to clear the infection [2]. Tissue scarring and an inability to clear bacteria often occur in these infections. Others possess ways of reducing inflammatory response to allow for better survival in the host. The scale of inflammatory response relies on the ability of the host

\footnotetext{
*Correspondence: s.ouburg@vumc.nl

${ }^{+}$Equal contributors

'Laboratory of Immunogenetics, Department of Medical Microbiology and Infection Control, VU University Medical Center, Amsterdam, The Netherlands Full list of author information is available at the end of the article
}

to detect the pathogen and initiate key inflammatory pathways.

One way of initiating inflammation is through the detection of bacterial DNA [3]. Bacterial DNA has unmethylated Cytosine-phosphor-Guanine (CpG) motifs, while mammals generally have methylated CpG motifs which are close to anti-inflammatory DNA sites [4-6]. Unmethylated CpG motifs are targets for the intracellular Toll-like receptor 9 (TLR9) [7]. This receptor is minimally, but consistently expressed in epithelial cells of the genital tract $[8,9]$. When TLR9 binds to specific unmethylated CpG motifs it activates the NF- $\mathrm{BB}$ pathway, which is a major pathway related to immune response. Activating this pathway initiates a chain reaction resulting in the release of pro-inflammatory cytokines including tumor necrosis factor- $\alpha$ (TNF- $\alpha$ ), interleukin-1 (IL-1), IL-6, IL-8, IL-12, and type 1 interferons $[4,10]$. These cytokines directly 
affect the cellular and humoral immune response as well as regulate the inflammation at the site of infection.

As inflammation is a main cause for symptoms in bacterial STDs, we look into how the CpG properties of these pathogens can explain differences in symptoms and outcomes of bacterial STDs, including: Haemophilus ducreyi, Chlamydia trachomatis, Neisseria gonorrhoeae, Treponema pallidum, and Mycoplasma genitalium.

The first group of pathogens; C. trachomatis, $N$. gonorrhoeae, and M. genitalium are STDs with similar symptoms and course of infection. These diseases are often asymptomatic, but can also show similar inflammation based symptoms during infection. These can range from mild cervicitis to pelvic inflammatory disease, ectopic pregnancy, and tubapathology associated infertility. It has been shown that activation of the NF-kB pathway through various TLRs is a vital part of the initial immune response to all of these diseases [11-14]. Previous study into the $\mathrm{CpG}$ properties of these pathogens showed that $C$. trachomatis serovars $\mathrm{C}$ and $\mathrm{D}$ have an immunostimulatory effect on the immune system while CpG properties of $N$. gonorrhoeae demonstrates a strong inhibitory potential towards TLR9 binding [12]. C. trachomatis serovars E and the highly inflammatory L2b, as well as various strains of $M$. genitalium will be analyzed for the first time in this study.

The second group of pathogens; T. pallidum and $H$. ducreyi are STDs that are characterized by ulcers and lesions on the genitals and skin during infection. It has been shown that NF- $\mathrm{KB}$ pathway activation through TLR stimulation is vital for initiating an immune response against T. pallidum $[15,16]$. However, this has not yet been shown for $H$. ducreyi infections. The cellular response to $H$. ducreyi, including macrophages and polymorphonuclear leukocytes, does suggests that cytokine signaling originating from NF- $\mathrm{kB}$ pathway activation plays a significant role in the infection $[17,18]$. CpG properties indicating a potentially strong activation potential of TLR9 could indicate the primary immune response during infection with these diseases.

Bacterial vaginosis is a disease of the genital tract commonly described as abnormal vaginal discharge, often accompanied with a foul smell, in women of childbearing age. There is no single causative agent of bacterial vaginosis. Instead it is caused by an imbalance in the natural vaginal microflora. One or more commensal bacteria overgrow the naturally dominant Lactobacilli. Some of the bacteria associated with bacterial vaginosis are Gardnerella vaginalis, Mycoplasma hominis, and Ureaplasma urealyticum. An immune response against bacterial vaginosis appears to be lacking. There are no polymorphonuclear leukocytes in the vaginal fluids of women with bacterial vaginosis, however it has been shown that inflammatory cytokines such as IL1 and TNF- $\alpha$ are present [19]. This suggests the imbalance of bacteria is recognized by the immune system, but an effective immune response is inhibited. Host response mechanisms to bacterial vaginosis appear to largely revolve around the activation of the NF- $\mathrm{kB}$ pathway [20-22].

Unlike these pathogens, commensal bacteria are naturally found in the host and generally cause no adverse effects. In this study we include the commensal bacteria Lactobacillus crispatus, Lactobacillus gasseri, and an Escherichia coli strain linked to asymptomatic growth in the urinary tract. $L$. crispatus is a beneficial vaginal bacterium whose decrease is characteristic of bacterial vaginosis. The vaginal bacterium $L$. gasseri is also found to protect the vagina from infections. Lactobacilli acidify the vagina and produce hydrogen peroxide which reacts with myeloperoxidase to form reactive molecules toxic to pathogens. Women without vaginal lactobacilli have an increased risk of HIV and gonorrhoeae [23, 24]. It has been shown that Lactobaccilli may or may not induce an immune response through the NF- $\mathrm{kB}$ pathway on a species dependent basis [25]. E. coli is a bacterium generally linked to intestinal inflammation and urinal tract infections. However, E. coli can also occur asymptomatically in both the intestines and the urinal tract [26]. The immunopathogenesis of E. coli has been clearly linked to the NF- $\mathrm{kB}$ pathway, primarily through activation of TLR4 [27, 28]. However this has only been shown for pathogenic strains.

In this study we aim to provide a broader view of the inflammatory properties of bacterial genomes in diseases related to the vaginal or genital tract. These genomes are analyzed in silico, to assess the inflammatory potential of CpG motifs in these pathogens, and to predict the role TLR9 plays in the respective host-bacterium interactions and whether strain differences affect this role.

\section{Methods}

Publicly available bacterial genome data has been used for all analyses in this study. NCBI genome databases have been used to obtain the genomes required for analysis. Genomes most focused on by the scientific community that did not have specific uncommon characteristics were chosen for the analysis. Genomes were chosen based on frequency of inclusion in research and lack of traits differentiating them from the usual organism. CpG analysis per genome has been done using previously described genome analysis methods [29]. These methods allowed determination of the amount and build of $\mathrm{CpG}$ motifs in a genome, predicted number of CpG motifs when looking at the genomes size, and GC content. The analyzed strains in this study comprise strains of the bacteria: C. trachomatis, E. coli, G. vaginalis, $H$. ducreyi, L. crispatus, L. gasseri, M. genitalium, $M$. hominis, $N$. gonorrhoeae, T. pallidum, and U. urealyticum as shown in Table 1. 
Table 1 Micro-organism names, strains and relevant NCBI references to sequences

\begin{tabular}{|c|c|c|c|}
\hline Bacteria & Disease & Strain & NCBI reference sequence \\
\hline H. ducreyi & Chancroid & HP35000 & NC_017456.1 \\
\hline C. trachomatis & Chlamydia & $E / 11023$ & NC_017431.1 \\
\hline C. trachomatis & Chlamydia & $E / 150$ & NC_017439.1 \\
\hline C. trachomatis & Chlamydia & E/SW3 & NC_017952.1 \\
\hline C. trachomatis & LGV & $\mathrm{L} 2 \mathrm{~b} / \mathrm{UCH}-1$ & NC_010280.2 \\
\hline N. gonorrhoeae & Gonorrhea & FA 1090 & NC_002946.2 \\
\hline N. gonorrhoeae & Gonorrhea & NCCP11945 & NC_011035.1 \\
\hline N. gonorrhoeae & Gonorrhea & TCDC-NG08107 & NC_017511.1 \\
\hline T. pallidum & Syphilis & DAL-1 & NC_016844.1 \\
\hline T. pallidum & Syphilis & SS14 & NC_010741.1 \\
\hline T. pallidum & Syphilis & Chicago & NC_017268.1 \\
\hline T. pallidum & Syphilis & Mexico A & NC_018722.1 \\
\hline M. genitalium & Non-gonococcal urethritis & G37 & NC_017456.1 \\
\hline M. genitalium & Non-gonococcal urethritis & M2288 & NC_018498.1 \\
\hline M. genitalium & Non-gonococcal urethritis & M2321 & NC_018495.1 \\
\hline M. genitalium & Non-gonococcal urethritis & M6282 & NC_018496.1 \\
\hline M. genitalium & Non-gonococcal urethritis & M6320 & NC_018497.1 \\
\hline G. vaginalis & Bacterial vaginosis & $409-05$ & NC_013721.1 \\
\hline G. vaginalis & Bacterial vaginosis & ATCC 14019 & NC_014644.1 \\
\hline G. vaginalis & Bacterial vaginosis & HMP 9231 & NC_017456.1 \\
\hline M. hominis & Bacterial vaginosis & ATCC 23144 & NC_013511.1 \\
\hline U. urealyticum & Bacterial vaginosis & ATCC 33699 & NC_011374.1 \\
\hline E. coli & - & ABU 83972 & NC_017631.1 \\
\hline L. crispatus & - & ST1 & NC_014106.1 \\
\hline L. gasseri & - & ATCC 33323 & NC_008530.1 \\
\hline
\end{tabular}

\section{In silico analyses}

Size and GC content of the analyzed genomes were gathered from the NCBI genome databases. The average amount of CpG hexameres (NNCGNN) per kb of genome was calculated from the total amount of $\mathrm{CpG}$ hexameres per genome. CpG hexameres found per genome were compared to the amount of $\mathrm{CpG}$ hexameres expected based on the size and the GC content of the genome. We determined the frequency of inflammation stimulatory or inhibitory CpG DNA motifs in their respective genomes $[12,29,30]$. As definition for stimulatory or inhibitory motifs we used published consensus motifs derived from E. coli sequences [30]. These comprise inhibitory hexamere motifs NCCGNN and NNCGRN, and stimulatory hexamere motifs RRCGYY. From the difference between these frequencies we produced $\mathrm{CpG}$ indices showing the $\mathrm{CpG}$ based immunostimulatory or immunoinhibitory potential of the disease as has previously been described [31, 32].

\section{Ethics statement}

The authors declare that no human material was used during this study.

\section{Results}

Table 2 shows the CpG indices for the examined microorganisms. An index above zero predicts immunostimulatory properties of the DNA and an index below zero predicts immunoinhibitory properties. The indices do not predict a set amount of inflammation. Larger indices indicate a more potent inflammatory or inhibitory potential. Amount of inflammation belonging to index values can be predicted by comparing scores and in vitro or in vivo responses.

G. vaginalis has the highest index with one strain reaching a value of 26.2, and a mean value of 23.9. Both the included E. coli strain and T. pallidum also appear to have larger than average mean $\mathrm{CpG}$ values, with mean values of 21.1 and 17.7, respectively. The lowest index belongs to $N$. gonorrhoeae with one strain having a CpG value of -79.5 and a mean $C p G$ value of -77.1 . $N$. gonorrhoeae was the only bacteria showing a negative $\mathrm{CpG}$ value in the analysis.

A large cluster of genomes were found to have relatively low mean $\mathrm{CpG}$ values of $<10$. The mean $\mathrm{CpG}$ value of C. trachomatis strains that were not L2b was 3.1, with the 
Table 2 Results of In silico $\mathrm{CpG}$ analyses

\begin{tabular}{|c|c|c|c|c|c|c|c|c|}
\hline \multicolumn{5}{|l|}{ Genome } & \multicolumn{4}{|c|}{ CpG hexamere deviation from expected values in $\%^{\mathrm{a}}$} \\
\hline Bacteria & Strain & Size $(\mathrm{Mb})$ & $G+C \%$ & $C p G$ per $\mathrm{kb}^{\mathrm{b}}$ & Total $\mathrm{CpG}^{\mathrm{c}}$ & Stimulatory $^{d}$ & Inhibitory ${ }^{e}$ & CpG index ${ }^{f}$ \\
\hline H. ducreyi & HP35000 & 1.7 & 38.2 & 41.0 & 112.2 & 124.8 & 110.4 & 6.6 \\
\hline C. trachomatis & $E / 11023$ & 1.04 & 41.3 & 33.8 & 79.3 & 90.7 & 79.1 & 3.1 \\
\hline C. trachomatis & $E / 150$ & 1.04 & 41.3 & 33.8 & 79.3 & 90.8 & 79.1 & 3.1 \\
\hline C. trachomatis & E/SW3 & 1.05 & 41.3 & 33.8 & 79.3 & 90.8 & 79.1 & 3.1 \\
\hline C. trachomatis & $\mathrm{L} 2 \mathrm{~b} / \mathrm{UCH}-1$ & 1.04 & 41.3 & 33.9 & 79.4 & 86.7 & 76.1 & 2.9 \\
\hline N. gonorrhoeae & FA 1090 & 2.15 & 52.7 & 92.2 & 132.9 & 83.9 & 143.5 & -73.1 \\
\hline N. gonorrhoeae & NCCP11945 & 2.24 & 52.4 & 90.7 & 132.3 & 80.3 & 145.8 & -78.6 \\
\hline N. gonorrhoeae & TCDC-NG08107 & 2.19 & 52.5 & 91.7 & 132.8 & 80.5 & 145.8 & -79.5 \\
\hline T. pallidum & Dal-1 & 1.14 & 52.8 & 75.1 & 107.8 & 107.5 & 85.7 & 17.7 \\
\hline T. pallidum & SS14 & 1.14 & 52.8 & 75.0 & 107.7 & 107.5 & 85.6 & 17.7 \\
\hline T. pallidum & Chicago & 1.14 & 52.8 & 75.1 & 107.8 & 107.6 & 85.7 & 17.7 \\
\hline T. pallidum & Mexico & 1.14 & 52.8 & 75.1 & 107.8 & 107.5 & 85.7 & 17.7 \\
\hline M. genitalium & G37 & 0.58 & 31.7 & 9.7 & 38.8 & 74.9 & 35.0 & 1.5 \\
\hline M. genitalium & M2288 & 0.58 & 31.7 & 9.8 & 38.9 & 75.0 & 35.2 & 1.5 \\
\hline M. genitalium & M2321 & 0.58 & 31.7 & 9.8 & 39.1 & 75.3 & 35.5 & 1.5 \\
\hline M. genitalium & M6282 & 0.58 & 31.7 & 9.8 & 39.1 & 74.4 & 35.5 & 1.5 \\
\hline M. genitalium & M6320 & 0.58 & 31.7 & 9.8 & 38.9 & 75.0 & 35.3 & 1.5 \\
\hline G. vaginalis & $409-05$ & 1.62 & 42.0 & 48.3 & 109.3 & 125.5 & 87.3 & 20.2 \\
\hline G. vaginalis & ATCC 14019 & 1.67 & 41.4 & 45.0 & 105.2 & 138.7 & 83.3 & 26.2 \\
\hline G. vaginalis & HMP 9231 & 1.73 & 41.2 & 44.4 & 104.7 & 137.3 & 83.1 & 25.2 \\
\hline M. hominis & ATCC 23144 & 0.67 & 27.1 & 12.8 & 69.4 & 113.1 & 70.0 & 3.8 \\
\hline U. urealyticum & ATCC 33699 & 0.87 & 25.8 & 13.8 & 82.9 & 138.2 & 64.3 & 8.4 \\
\hline E. coli & ABU 83972 & 5.13 & 50.6 & 49.2 & 111.7 & 146.6 & 108.2 & 21.1 \\
\hline L. crispatus & ST1 & 2.04 & 36.9 & 27.5 & 80.8 & 96.6 & 80.0 & 3.7 \\
\hline L. gasseri & ATCC 33323 & 1.89 & 35.3 & 23.4 & 75.4 & 99.0 & 73.0 & 4.6 \\
\hline
\end{tabular}

${ }^{\mathrm{a}}$ Deviations in amounts of CpG hexameres compared to the expected amount based on GC content

${ }^{b} \mathrm{CpG}$ hexameres occurring per $1 \mathrm{~kb}$ of DNA

'Total number of $\mathrm{CpG}$ hexameres compared to the expected amount

${ }^{\mathrm{d}}$ Number of stimulatory CpG hexameres (RRCGYY) compared to expected amount

${ }^{\mathrm{e}}$ Number of inhibitory CpG hexameres (NCCGNN and NNCGRN) compared to the expected amount

Index calculated from the difference between stimulatory deviation and inhibitory deviation indices, multiplied by the total CpG index, normalized by multiplying with the amount of $\mathrm{CpG}$ hexameres per $1 \mathrm{~kb}$

included L2b strain showing a slightly lower CpG value of 2.9. $H$. ducreyi showed a CPG value of 6.6. The two included Mycoplasma species, genitalium and hominis, were found to have mean CpG values of 1.5 and 3.8, respectively. The single strain of $U$. urealyticum was found to have a CpG value of 8.4. Lastly, the Lactobacilli were found to have index values of 3.7 and 4.6. Figure 1 shows the mean CpG index values for every pathogen on a CpG axis.

\section{Discussion}

The immune response to bacterial STDs is primarily initiated through activation of TLRs. TLR9 is likely to be a big factor due to activation of the receptor by bacterial DNA CpG motifs. This study has produced an overview of potential TLR9 activation through inflammation stimulating or inhibiting CpG motifs related to a variety of bacterial STDs, bacteria linked to bacterial vaginosis, and commensal bacteria found in the genital tract.

The group of bacterial STDs with symptoms largely related to symptoms induced by inflammation in the host was a likely target to show high potential TLR9 activation through the CpG indices. Surprisingly, C. trachomatis, $N$. gonorrhoeae, and M.genitalium do not show any indices higher than 3.1. Although there is a relatively low $\mathrm{CpG}$ index for both $C$. trachomatis serovars $\mathrm{E}$ and L2b, cervical and colonic epithelial cells infected with $C$. trachomatis do secrete pro-inflammatory cytokines in relatively large amounts [33]. Additionally, 


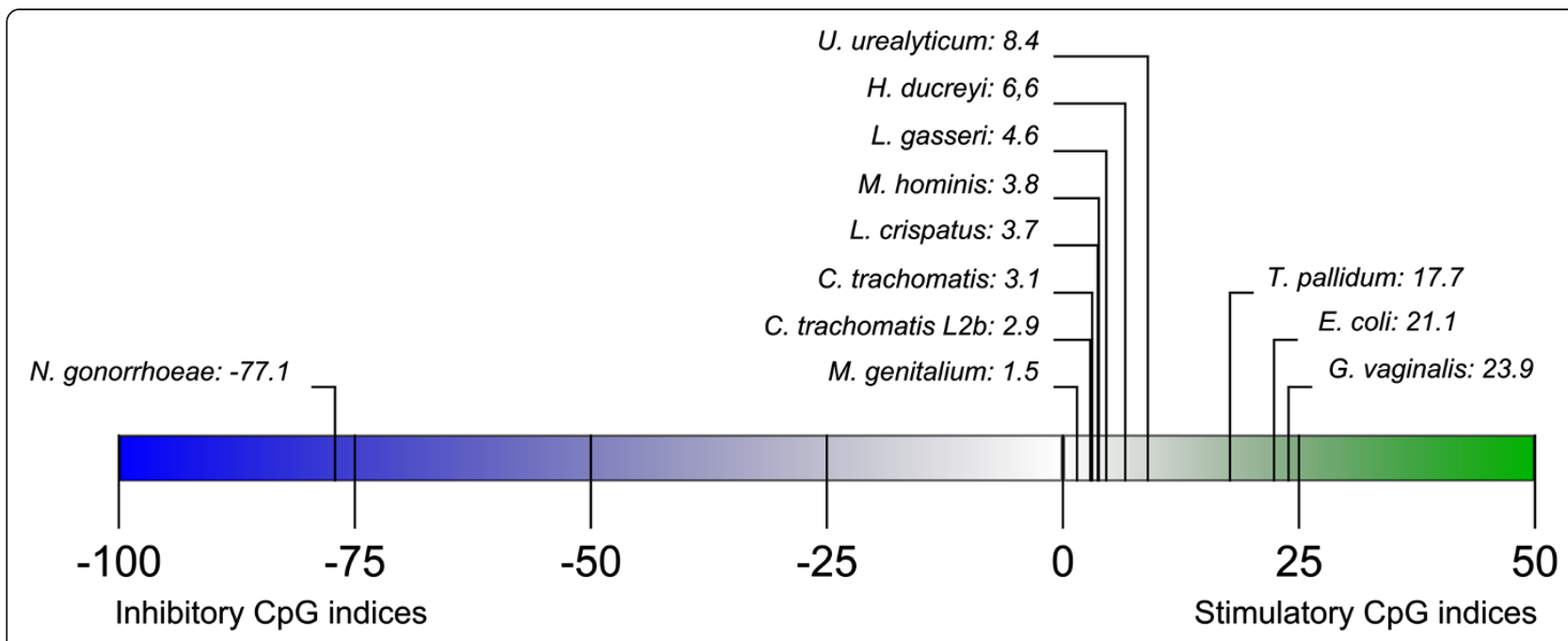

Fig 1 Scale bar showing the position of the mean CpG values per pathogen

IL-1 $\alpha$ secreted by endocervical epithelial cells was previously found to amplify the inflammatory response by stimulating additional cytokine production without activating more TLRs [34]. A study by Ouburg et al. shows that TLR9 does not influence the susceptibility to acute Chlamydia infection [12]. This information plus the relatively low stimulatory $\mathrm{CpG}$ index of 3.1 of C. trachomatis may indicate that it elicits an immune response via another route than TLR9. TLR4 is a likely alternative candidate, as it recognizes chlamydial LPS via its coreceptor CD14 [35]. Similarly, the highly inflammatory strain L2b/UHC-1 shows a comparable CpG index also suggesting that TLR9 and CPG DNA are not vital factors in inflammation during C. trachomatis infection.

Similarly to C. trachomatis, symptoms during infection with $N$. gonorrhoeae are also largely based on inflammation. However it was found to have an inhibitory CpG index of -73.1 , similar to findings in a study by Ouburg et al. [12]. It has been described that $N$. gonorrhoeae uses several strategies to avoid the immune system. The CpG index of -73.1 of $N$. gonorrhoeae may explain that this pathogen suppresses Th1 and Th2 responses by reducing binding with TLR9 and activation of NF- $\mathrm{kB}$ [36]. This reduces the secretion of IL- 4 and IL-12 that are needed to activate the Th1 and Th2 responses. Reports show that shortly after infection, CD4+ T cell and CD8+ $\mathrm{T}$ cell levels declined [37]. This may also explain why $N$. gonorrhoeae demonstrates an asymptomatic clinical course in most cases [38]. Based on these studies, it is likely that when inflammatory symptoms arise during $N$. gonorrhoeae infection, it is likely through activation of the immune response without activation of TLR9.

M. genitalium was found to have a minimal $\mathrm{CpG}$ index of only 1.5. Comparing this with the minor CpG index for M. hominis of 3.8 and a higher $\mathrm{CpG}$ index of 8.4 for the closely related $U$. urealyticum some similarities can be seen. The values suggest minor inflammatory properties of the micro-organisms' DNA and significance of TLR9 in the inflammatory response to these organisms. No research has been done on the roles of either CpG or the TLR9 pathway in the bacteria. However, a previous study did indicate TLR1 and TLR2 to induce the NF- $\mathrm{kB}$ pathway in M. genitalium [14]. Therefore, we suggest that activation of the immune response is largely initiated through these pathways instead.

The bacterial STDs $H$. ducreyi and T. pallidum, both characterized by the formation of lesions or ulcers as symptoms, showed CpG indices of 6.6 and 17.7, respectively. During $H$. ducreyi infections, increased secretion of TLR9 related pro-inflammatory cytokines including IL-12 and IFNy would activate and increase differentiation of Th1 cells. A Th1 cellular immune response is needed for clearance of $H$. ducreyi [39]. The effect of some point mutations in TLR9 on activation of the cellular immune response was shown by Sanders et al., showing a protective effect of TLR9 2848 in a study targeting bacterial meningitis [31]. Unpublished data from our group showed a protective association for $T L R 9+2848^{*} \mathrm{G}$ and a significant risk enhancing effect for TLR9 $-1237^{*}$ T plus TLR9 + 2848*A during H. ducreyi infections (manuscript in preparation). This indicates TLR9 activation through CpG motifs in $H$. ducreyi DNA is vital for a proper immune response to this infection

Similarly during T. pallidum infections a cellular immune response is vital for clearance of the infection [40]. With pro-inflammatory cytokines being found inside lesions, indicating activation of the NF- $\mathrm{kB}$ pathway plays an important role in the initial immune response as well as activation of the cellular response. The relatively high CpG index of 17.7 found for T. pallidum indicates that 
TLR9 can be the primary inducer of the NF- $\mathrm{kB}$ pathway during infection with T. pallidum.

G. vaginalis was found to have the highest mean CpG index of 25.7, suggesting that it has DNA with significant inflammatory properties. However, bacterial vaginosis because of $G$. vaginalis overgrowth only produces mild inflammatory signs. G. vaginalis has previously been found to create a biofilm and from there induce controlled inflammation, using the host's immune response to further its infection [41]. Additionally, Ghione et al. has found that a Th2 response activating B-cells produces antibodies specific to G. vaginalis influencing the infection but not clearing it [42]. We suggest that the high CpG index found in this study can be explained as part of the way G. vaginalis gains advantage from the inflammation while inside a biofilm.

The commensal bacteria L. gasseri and L. crispatus show a stimulatory effect on the immune system. In contrast to our findings, a study by Ghadimi et al. describes that the binding of the commensal bacteria L. rhamnosus to TLR9 elicits an intracellular signaling cascade in a manner that reduces the expression of IL-8. TNF- $\alpha$ is being attenuated by reducing $I k B \alpha$ and $p 38$ phosphorylation, which are downstream signaling proteins in the NF- $\mathrm{kB}$ pathway [43]. Additionally, recent findings suggest that there is a species specific effect on the inflammatory response of the host to Lactobaccillus spp. [25]. For example L. iners was found to induce pathogen recognition receptor activity and expression of pro-inflammatory cytokines. Conversely, L. crispatus was found to not exhibit these effects. This suggests a potential disparity between different Lactobaccillus species that may explain the different findings. Indeed, one study found that cytokine production differed between Lactobacillus species, and that this cytokine response is primarily due to activation of TLR9 [44]. This may indicate that the relatively small difference between the two species examined here is a fluctuation that apparently has an in vivo effect on the production of TLR9 related cytokines.

In contrast to the relatively low $\mathrm{CpG}$ indices of the examined Lactobacilli, the examined E. coli strain showed a high immunostimulatory CpG index of 21.1. Although studies into commensal $E$. coli strains have primarily focused on TLR4 and TLR5, one study has shown cytokine expression profiles during stimulation of TLR9 with commensal E. coli DNA linked to NF- $\mathrm{kB}$ activation [45-47]. It is strange then, that the presence of the $E$. coli strain does not lead to symptoms that normally occur during $E$. coli pathogenic infections. Previous analysis of the E. coli ABU 83972 genome found that the innate immune response of the host is modified during infection with this bacterium [26]. Specifically the IL-1 and IL-6 signaling pathways are affected. The authors suggest that the bacteria uses this modified immune response to adapt on a host-specific basis, to a point where both host and bacterium can benefit from the commensal growth. Therefore, in this specific strain of $E$. coli the immunostimulatory potential of the high CpG index is successfully circumvented.

Comparing our results to previous studies into $\mathrm{CpG}$ indices of microbial organisms allows us to put the CpG indices into context [31, 32]. Lundberg et al. examined viral DNA to find CpG indices up to 148.7 for Bovine Herpesvirus-1 and a low of -9.4 for Epstein Barr virus. They suggest that viral DNA characteristics make it hard to compare $\mathrm{CpG}$ indices of these viruses, and mention that the results may have been affected by the $\mathrm{CpG}$ motifs used for analysis, as they were determined from bacterial DNA. Nevertheless, they showed a predictive value in the $\mathrm{CpG}$ index as the negative results relate to low inflammation in clinical infections and relatively high results relate to strong inflammatory responses in vivo [32]. The study of Sanders et al. focused on bacterial meningitis and can be better related to this study. Interestingly, their analyses of $N$. mengitidis resulted in a CpG index of -106.8 , suggesting a very strong immunoinhibitory relation similar to the one found in this study for N. gonorrhoeae. H. ducreyi has a CpG index of 6.6, only 0.6 points removed from $H$. influen$z e a$ with an index of 7.2. Sanders et al. relate even the weak CPG indices to clinical inflammation during their respective diseases [31].

Looking at the clinical pictures of pathogens included in this study, the bacteria $H$. ducreyi and T. pallidum cause visible soars or ulcers during their clinical course while C. trachomatis, N. gonorrhoeae, and M. genitalium have the shared characteristic of causing tubal pathology, which in all cases can lead to infertility and ectopic pregnancy. The ulcer and lesion producing group has $\mathrm{CpG}$ indices that are overall higher than the group of pathogens related to tubapathology, even though the clinical course of the last group of diseases shows clear inflammation in the host. However, previous studies have shown that pathogens related to tubapathology are detected more accurately through other pathways. The difference in CpG index values in this group may be explained by the fact that $C$. trachomatis is intracellular, and $N$. gonorrhoeae extracellular, thus the two are exposed to different immunological factors. This has already been shown for $M$. genitalium, which is detected through TLR1 and TLR2 instead [14]. There are also two nonpathogenic groups of bacteria studied here. The first is the commensal group including L. crispatus, L. gasseri, and an asymptomatic $E$. coli strain. The second is the bacterial vaginosis group consisting of G. vaginalis, $M$. hominis, and $U$. urealyticum. These may show symptoms like increased vaginal discharge, change of smell, and itchiness [48]. These two groups both show widely varying positive $\mathrm{CpG}$ indices depending on the examined organism. This indicates that TLR9 initiation potential is likely highly specific to an 
organism, and related to multiple factors such as interaction with the immune system. Additionally, it suggests that CpG/TLR9 interaction alone cannot account for all specific inflammatory symptoms. A previous study has shown that bacterial $\mathrm{CpG}$ specifically induces the proinflammatory cytokines IL-6, IL-12, and Interferon $\gamma$ [49]. However, the symptoms created during infection with the included organisms are formed by a complex system including both host and bacterial factors for which the $\mathrm{CpG}$ index value reflects the intensity of the initial inflammation.

Including all the studied bacteria into one biological model is difficult, as many of these bacteria have different ways of avoiding or interacting with the immune system. However, the comparison of CpG indices with clinical outcomes of the diseases showed that there are similar characteristics between some bacteria. As was previously mentioned, positive $\mathrm{CpG}$ indices result in stimulation of TLR9, which activates the TLR9 related NF- $\kappa B$ pathway. At the end of this pathway, upregulated transcription of NF- $\mathrm{kB}$ targeted genes causes more inflammatory cytokines such as IL-1 and TNF- $\alpha$ to be released. We suggest that a relatively low or negative $\mathrm{CpG}$ index still allows the DNA of the bacteria to bind. However, this DNA then does not stimulate TLR9, or does not stimulate TLR9 as strongly into activating the NF- $\mathrm{kB}$ pathway. Conversely, a positive CpG index means the DNA binds to TLR9 more easily or activates the NF- $\mathrm{kB}$ pathway in a stronger manner.

Reflecting back on this study some strengths become clear. The methods used in this study have previously been shown to have significant predictive value. This study is also the first to look at CpG DNA and its effect on inflammation for such a large group of relevant bacteria in the genital tract. However, some limitations do apply. Though the predictions have previously been shown to have significant value, in vitro study is needed for verification. Also this study has only looked at sequenced strains. Therefore some results may not be in line with what can be seen in infections with current wild type strains in in vivo infections. Additionally, the used $\mathrm{CpG}$ sequences were all derived from studies on E. coli. There is no study into whether these sequences act like stimulatory and inhibitory motifs for all the bacteria studied here or if there are any additional relevant sequences.

This study has indicated inflammatory potential in bacterial STDs through analysis of the bacterial genomes. If this result can be corroborated in vitro it can clarify the immunopathogenesis for the bacteria studied here. In the future this data can be used to specifically focus research into inflammation during infections with the studied bacteria. Additionally, results found in this study can be used to compare indices of other microorganisms studied using the same methods.

\section{Conclusion}

In conclusion our results show varying $\mathrm{CpG}$ index values between bacterial species. Comparison of $\mathrm{CpG}$ indices with the clinical course of several pathogens shows the CpG index helps clarify the clinical course of infection. However, we found no links between CpG index values and either obligate pathogenicity or facultative pathogenicity through bacterial vaginosis. Lactobacilli showed relatively low $\mathrm{CpG}$ indices which do suggest a lower inflammatory potential from these bacteria.

\section{Abbreviations \\ CpG: Cytosine-phosphor-Guanine group; GTI: Genital tract infection; IL: Interleukin; STD: Sexually transmitted disease; TLR: Toll-like receptor TNF: Tumor Necrosis Factor.}

\section{Competing interests}

The authors declare that they have no competing interests.

\section{Authors' contributions}

MS and DdW participated in the design of the study, carried out the genome analyses and drafted the manuscript. SM and SO conceived and participated in the design of the study. They also coordinated the study and helped finalize the manuscript. All authors read and approved the final manuscript.

\section{Author details}

${ }^{1}$ Laboratory of Immunogenetics, Department of Medical Microbiology and Infection Control, VU University Medical Center, Amsterdam, The Netherlands. ${ }^{2}$ Institute of Public Health Genomics, Department of Genetics and Cell Biology, Research Institutes CAPHRI and GROW, Faculty of Health, Medicine \& Life Sciences, University of Maastricht, Maastricht, The Netherlands.

Received: 17 April 2015 Accepted: 8 July 2015

Published online: 16 July 2015

\section{References}

1. Satterwhite $\mathrm{CL}$, Torrone E, Meites E, Dunne EF, Mahajan R, Ocfemia MC, et al. Sexually transmitted infections among US women and men: prevalence and incidence estimates, 2008. Sex Transm Dis. 2013:40:187-93. doi:10.1097/OLQ.0b013e318286bb53.

2. Katz AR, Lee MV, Wasserman GM. Sexually transmitted disease (STD) update: a review of the CDC 2010 STD treatment guidelines and epidemiologic trends of common STDs in Hawai'i. Hawaii J Med Public Health. 2012;71:68-73.

3. Krieg AM. CpG motifs in bacterial DNA and their immune effects. Annu Rev Immunol. 2002:20:709-60. doi:10.1146/annurev.immunol.20.100301.064842.

4. Krieg AM, Yi AK, Matson S, Waldschmidt TJ, Bishop GA, Teasdale R, et al. CpG motifs in bacterial DNA trigger direct B-cell activation. Nature. 1995:374:546-9. doi:10.1038/374546a0.

5. Krieg AM, Wu T, Weeratna R, Efler SM, Love-Homan L, Yang L, et al. Sequence motifs in adenoviral DNA block immune activation by stimulatory CpG motifs. Proc Natl Acad Sci U S A. 1998;95:12631-6.

6. Bird AP, Taggart MH, Nicholls RD, Higgs DR. Non-methylated CpG-rich islands at the human alpha-globin locus: implications for evolution of the alpha-globin pseudogene. EMBO J. 1987;6:999-1004.

7. Hemmi H, Takeuchi O, Kawai T, Kaisho T, Sato S, Sanjo H, et al. A Toll-like receptor recognizes bacterial DNA. Nature. 2000;408:740-5. doi:10.1038/ 35047123

8. Andersen JM, Al-Khairy D, Ingalls RR. Innate immunity at the mucosal surface: role of toll-like receptor 3 and toll-like receptor 9 in cervical epithelial cell responses to microbial pathogens. Biol Reprod. 2006;74:824-31. doi:10.1095/biolreprod.105.048629.

9. Herbst-Kralovetz MM, Quayle AJ, Ficarra M, Greene S, Rose WA, Chesson R, et al. Quantification and comparison of toll-like receptor expression and responsiveness in primary and immortalized human female lower genital tract epithelia. Am J Reprod Immunol. 2008;59:212-24. doi:10.1111/j. 1600-0897.2007.00566.x. 
10. Krieg AM. CpG DNA: a novel immunomodulator. Trends Microbiol. 1999;7:64-5.

11. Karimi O, Ouburg S, de Vries HJ, Pena AS, Pleijster J, Land JA, et al. TLR2 haplotypes in the susceptibility to and severity of Chlamydia trachomatis infections in Dutch women. Drugs Today (Barc). 2009;45 Suppl B:67-74. 4599.

12. Ouburg S, Lyons JM, Land JA, Den Hartog JE, Fennema JS, de Vries HJ, et al. TLR9 KO mice, haplotypes and CPG indices in Chlamydia trachomatis infection. Drugs Today (Barc). 2009;45 Suppl B:83-93. 4599.

13. Massari $P$, Ram S, Macleod H, Wetzler LM. The role of porins in neisserial pathogenesis and immunity. Trends Microbiol. 2003;11:87-93.

14. Shimizu T, Kida Y, Kuwano K. A triacylated lipoprotein from Mycoplasma genitalium activates NF-kappaB through Toll-like receptor 1 (TLR1) and TLR2. Infect Immun. 2008;76:3672-8. doi:10.1128/IAI.00257-08.

15. Lien E, Sellati TJ, Yoshimura A, Flo TH, Rawadi G, Finberg RW, et al. Toll-like receptor 2 functions as a pattern recognition receptor for diverse bacterial products. J Biol Chem. 1999;274:33419-25.

16. Brightbill HD, Libraty DH, Krutzik SR, Yang RB, Belisle JT, Bleharski JR, et al. Host defense mechanisms triggered by microbial lipoproteins through toll-like receptors. Science. 1999;285:732-6. 7722.

17. Bauer ME, Goheen MP, Townsend CA, Spinola SM. Haemophilus ducreyi associates with phagocytes, collagen, and fibrin and remains extracellular throughout infection of human volunteers. Infect Immun. 2001;69:2549-57. doi:10.1128/IAl.69.4.2549-2557.2001.

18. Bauer ME, Townsend CA, Ronald AR, Spinola SM. Localization of Haemophilus ducreyi in naturally acquired chancroidal ulcers. Microbes Infect. 2006;8:2465-8. doi:10.1016/j.micinf.2006.06.001.

19. Sturm-Ramirez K, Gaye-Diallo A, Eisen G, Mboup S, Kanki PJ. High levels of tumor necrosis factor-alpha and interleukin-1beta in bacterial vaginosis may increase susceptibility to human immunodeficiency virus. J Infect Dis. 2000;182:467-73. doi:10.1086/315713.

20. Zariffard MR, Novak RM, Lurain N, Sha BE, Graham P, Spear GT. Induction of tumor necrosis factor- alpha secretion and toll-like receptor 2 and 4 mRNA expression by genital mucosal fluids from women with bacterial vaginosis. J Infect Dis. 2005;191:1913-21. doi:10.1086/429922.

21. Goepfert AR, Varner M, Ward K, Macpherson C, Klebanoff M, Goldenberg RL, et al. Differences in inflammatory cytokine and Toll-like receptor genes and bacterial vaginosis in pregnancy. Am J Obstet Gynecol. 2005;193:1478-85. doi:10.1016/j.ajog.2005.03.053.

22. Libby EK, Pascal KE, Mordechai E, Adelson ME, Trama JP. Atopobium vaginae triggers an innate immune response in an in vitro model of bacterial vaginosis. Microbes Infect. 2008;10:439-46. doi:10.1016/ j.micinf.2008.01.004.

23. Antonio MA, Hillier SL. DNA fingerprinting of Lactobacillus crispatus strain CTV-05 by repetitive element sequence-based PCR analysis in a pilot study of vaginal colonization. J Clin Microbiol. 2003;41:1881-7.

24. Machado A, Jefferson KK, Cerca N. Interactions between Lactobacillus crispatus and Bacterial Vaginosis (BV)-Associated Bacterial Species in Initial Attachment and Biofilm Formation. Int J Mol Sci. 2013;14:12004-12. doi:10.3390/ijms140612004.

25. Doerflinger SY, Throop AL, Herbst-Kralovetz MM. Bacteria in the vaginal microbiome alter the innate immune response and barrier properties of the human vaginal epithelia in a species-specific manner. J Infect Dis. 2014;209:1989-99. doi:10.1093/infdis/jiu004.

26. Zdziarski J, Brzuszkiewicz E, Wullt B, Liesegang H, Biran D, Voigt B, et al. Host imprints on bacterial genomes-rapid, divergent evolution in individual patients. PLoS Pathog. 2010;6, e1001078. doi:10.1371/journal.ppat.1001078.

27. Justice SS, Hunstad DA, Seed PC, Hultgren SJ. Filamentation by Escherichia coli subverts innate defenses during urinary tract infection. Proc Natl Acad Sci U S A. 2006;103:19884-9. doi:10.1073/pnas.0606329104.

28. Lee JS, Frevert CW, Matute-Bello G, Wurfel MM, Wong VA, Lin SM, et al. TLR-4 pathway mediates the inflammatory response but not bacterial elimination in E. coli pneumonia. Am J Physiol Lung Cell Mol Physiol. 2005;289:L731-8. doi:10.1152/ajplung.00196.2005.

29. Bikandi J, San MR, Rementeria A, Garaizar J. In silico analysis of complete bacterial genomes: PCR, AFLP-PCR and endonuclease restriction. Bioinformatics. 2004;20:798-9. doi:10.1093/bioinformatics/btg491.

30. Bauer S, Kirschning CJ, Hacker H, Redecke V, Hausmann S, Akira S, et al. Human TLR9 confers responsiveness to bacterial DNA via species-specific CpG motif recognition. Proc Natl Acad Sci U S A. 2001;98:9237-42. doi:10.1073/pnas.161293498.

31. Sanders MS, van Well GT, Ouburg S, Lundberg PS, van Furth AM, Morre SA. Single nucleotide polymorphisms in TLR9 are highly associated with susceptibility to bacterial meningitis in children. Clin Infect Dis. 2011:52:475-80. doi:10.1093/cid/ciq155.

32. Lundberg P, Welander P, Han X, Cantin E. Herpes simplex virus type 1 DNA is immunostimulatory in vitro and in vivo. J Virol. 2003;77:11158-69.

33. Rasmussen SJ, Eckmann L, Quayle AJ, Shen L, Zhang YX, Anderson DJ, et al. Secretion of proinflammatory cytokines by epithelial cells in response to Chlamydia infection suggests a central role for epithelial cells in chlamydial pathogenesis. J Clin Invest. 1997;99:77-87. doi:10.1172/JCI119136.

34. Darville T, Hiltke TJ. Pathogenesis of genital tract disease due to Chlamydia trachomatis. J Infect Dis. 2010;201 Suppl 2:S114-25.

35. Den Hartog JE, Lyons JM, Ouburg S, Fennema JS, de Vries HJ, Bruggeman CA, et al. TLR4 in Chlamydia trachomatis infections: knockout mice, STD patients and women with tubal factor subfertility. Drugs Today (Barc). 2009;45 Suppl B:75-82.

36. Liu Y, Islam EA, Jarvis GA, Gray-Owen SD, Russell MW. Neisseria gonorrhoeae selectively suppresses the development of Th1 and Th2 cells, and enhances Th17 cell responses, through TGF-beta-dependent mechanisms. Mucosal Immunol. 2012;5:320-31. doi:10.1038/mi.2012.12.

37. Russell MW, Mestecky J. Tolerance and protection against infection in the genital tract. Immunol Invest. 2010;39:500-25. doi:10.3109/08820131003674834

38. Conejero C, Cannoni G, Merino PM, Bollmann J, Hidalgo C, Castro M, et al. Screening of Neisseria gonorrhoeae and Chlamydia trachomatis using techniques of self collected vaginal sample in young women. Rev Chilena Infectol. 2013;30:489-93. doi:10.4067/S0716-10182013000500004.

39. Janowicz DM, Ofner S, Katz BP, Spinola SM. Experimental infection of human volunteers with Haemophilus ducreyi: fifteen years of clinical data and experience. J Infect Dis. 2009;199:1671-9. doi:10.1086/598966.

40. Cruz AR, Ramirez LG, Zuluaga AV, Pillay A, Abreu C, Valencia CA, et al. Immune evasion and recognition of the syphilis spirochete in blood and skin of secondary syphilis patients: two immunologically distinct compartments. PLoS Negl Trop Dis. 2012;6, e1717. doi:10.1371/ journal.pntd.0001717.

41. Saunders S, Bocking A, Challis J, Reid G. Effect of Lactobacillus challenge on Gardnerella vaginalis biofilms. Colloids Surf B Biointerfaces. 2007;55:138-42. doi:10.1016/j.colsurfb.2006.11.040.

42. Ghione M, Clerici PA, Piragine G, Magliano E. Humoral circulatory immune response to Gardnerella vaginalis. J Clin Microbiol. 1989;27:2138-9.

43. Ghadimi D, Folster-Holst R, de VM, Winkler P, Heller KJ, Schrezenmeir J. Effects of probiotic bacteria and their genomic DNA on TH1/TH2-cytokine production by peripheral blood mononuclear cells (PBMCs) of healthy and allergic subjects. Immunobiology. 2008;213:677-92. doi:10.1016/ j.imbio.2008.02.001.

44. Plantinga TS, van Maren WW, van BJ, Hameetman M, Nierkens S, Jacobs C, et al. Differential Toll-like receptor recognition and induction of cytokine profile by Bifidobacterium breve and Lactobacillus strains of probiotics. Clin Vaccine Immunol. 2011;18:621-8. doi:10.1128/CVI.00498-10.

45. Rachmilewitz D, Katakura K, Karmeli F, Hayashi T, Reinus C, Rudensky B, et al. Toll-like receptor 9 signaling mediates the anti-inflammatory effects of probiotics in murine experimental colitis. Gastroenterology. 2004;126:520-8.

46. Heimesaat MM, Fischer A, Jahn HK, Niebergall J, Freudenberg M, Blaut M, et al. Exacerbation of murine ileitis by Toll-like receptor 4 mediated sensing of lipopolysaccharide from commensal Escherichia coli. Gut. 2007:56:941-8. doi:10.1136/gut.2006.104497.

47. Bambou JC, Giraud A, Menard S, Begue B, Rakotobe S, Heyman M, et al. In vitro and ex vivo activation of the TLR5 signaling pathway in intestinal epithelial cells by a commensal Escherichia coli strain. J Biol Chem. 2004;279:42984-92. doi:10.1074/jbc.M405410200.

48. Casari E, Ferrario A, Morenghi E, Montanelli A. Gardnerella, Trichomonas vaginalis, Candida, Chlamydia trachomatis, Mycoplasma hominis and Ureaplasma urealyticum in the genital discharge of symptomatic fertile and asymptomatic infertile women. New Microbiol. 2010;33:69-76.

49. Klinman DM, Yi AK, Beaucage SL, Conover J, Krieg AM. CpG motifs present in bacteria DNA rapidly induce lymphocytes to secrete interleukin 6, interleukin 12, and interferon gamma. Proc Natl Acad Sci U S A. 1996;93:2879-83. 